\title{
INDUSTRIES AS VECTORS OF REGIONAL COMPETITIVENESS CASE STUDY - THE NORTH-WEST REGION OF ROMANIA
}

\author{
Oana Stănculescu ${ }^{l}$
}

\begin{abstract}
The aspects of regional competitiveness have become an important part of regional development strategies. Most regions are trying to focus on niches which could bring sustainable economic and social development, but this can be achieved through two important strategic planning stages: measurement of the competitive position and the identification of the regional potential.

No region is able to specialize and develop competitive advantages in all industries, but it has some, either traditional or emerging, in which it focuses its resources, hoping that in the future they will properly determine the regional identity and specificity. Based on the idea that no region can become competitive in all its industries, it became a priority to identify the industries that generate regional economic growth. In the present paper, we intend to pinpoint which are the most competitive industries that characterize the North-West region's economy, through methods that can help us make a strategic decision regarding the fields that should be supported in the future. The analysis will take into account relevant indicators from each industry: number of firms, employees, and turnover.
\end{abstract}

Keywords: region, competitiveness, industry, decision, strategy

JEL Codes: L60, O12, O18

\section{Introduction}

Our paper is like a case study. In the next pages, we will try to present a scenario in which we'll highlight a situation, in a concrete framework, with concrete tools and actors involved. The data used in the case study are provided by the National Institute of Statistics. Some of the aspects presented in the case are real, and some are just hypothetical. The case study will help the reader understand an actual situation which involves a decision making process.

\section{The situation}

We'll start describing the study with the presentation of a non-profit institution within the region. The objectives of this institution are to support the development of the North-West Region, to promote business efficiency, investment and competitiveness, to promote employment, to improve the quality and standard of life of its inhabitants and to contribute to sustainable development.

Besides these, the institution has strategic planning abilities, being involved in the elaboration of the Regional Development Plan. In this context, the institution has the role in identifying the most competitive industries that should be supported in the future.

\section{The North-West Region - general characteristics}

The North-West Region of Romania is one of the eight Romanian regions. The total surface of the region is $34.160 \mathrm{~km}^{2}$ (14\% of the Romania's total surface) and its 2.600 .132 inhabitants

\footnotetext{
1 PhD. Student, Faculty of Economics and Business Administration, Babeş-Bolyai University, Cluj-Napoca, stanculescu.oana@yahoo.com
} 
enjoyed low to medium standards of living (the GDP per capita was around 5300 euro, almost 21 in percentage of the EU average). The region is composed of six counties: Bihor, Bistriţa-Năsăud, Cluj, Maramureş, Satu Mare and Sălaj, very different in terms of economic structure.

The North-West Region has a strategic geographical position, being situated at the borders with Hungary and Ukraine, but also with the Center, West and North-East development regions from Romania. The most important cities are Cluj-Napoca, Baia Mare, Oradea, Zalău, Satu Mare and Bistriţa, which are considered regional poles for economic development. In terms of economic attractiveness, the region is appealing to the investors due to the labor market, to the salaries, but also to the business environment, inputs of modern technologies and to the tradition in specific industries. The majority of the investors are coming from countries like Germany, Italy, Austria, France, UK, Spain, Hungary and they choose to invest mostly in industries like electrical equipment, structural metal products, wood and furniture industry, textiles and food.

The region's economy is mainly based on the tertiary sector, which contributes with almost $50 \%$ to the regional Gross Value Added (GVA) and on the industry, as a second sector, with a contribution of $34 \%$. The tertiary sector is relying especially on the commercial services (trade, hotels and restaurants, transport and storage, information and communication), with $35 \%$ of the total GVA generated by the service sector, and followed by the public (33\%) and the financial and real estate services, which have greatly contributed with $32 \%$.

The main exports are industrial products like footwear, furniture, electrical machinery. Also, one of the highest values of exports is registered for textiles and apparel. As a general observation, the industries from the North-West region have, in addition to their relatively low value added, a low technological content and their development is based on the cheap labor costs and on imported materials. Even tough the complexity of the regional economy is given by the heterogeneity of the counties' economies most of them still have an economic structure based on traditional industries. The disparities in the economic development of the six counties are high such that the counties from the southern and western part of the region are more industrialized and economically stable than the counties from the center and eastern part, where the evolution has resulted in the loss of competitive ability and competitive advantages in several branches.

Businesses in North-West Region are mainly small and medium sized. Over $97 \%$ of the companies employed fewer than 50 people. From the total number of companies, only $12 \%$ of them have an industrial profile, of which the highest concentration levels can be observed in the food industry, manufacture of fabricated metal products, manufacture of wood and furniture.

The key challenges for the North-West region are to increase productivity, employment, competitiveness and innovation and to transform old traditional industries into new high-value added business opportunities, which can ensure the future prosperity and growth of the region.

The institution that we've described earlier in the paper has also the responsibility of choosing from the region's industries in order to give support for the sustainable development and to ensure the promotion of the most competitive products on the international markets, which reflect regional specificities.

Now the question is what industries should the institution support and promote in the future? Which should be the decision-maker's (the institution's representative) choice?

\section{Methodology}

The evaluation of industries' competitiveness is a decisional process and there are many ways in which a decision can be made. It often implies the feeling of the decision maker, but is not always enough. A decision-maker has the responsibility in arguing its choices, especially when the choice implies financial support. The most appropriate way of this process is to combine the quantitative with qualitative methods in order to achieve a hierarchy of certain industries that the "numbers" (quantitative) and the specialists (qualitative) prove to have development potential in the 
future in order to face the challenges identified above. In this case, we'll restrict the research by appealing to quantitative methods.

The institution's decision-maker has chosen two methods in order to help him decide and to prioritize the industries: the analytic hierarchy process and the global utility method, both of them often used for organizing and analyzing complex decisions.

The AHP method is accessible and it usually implies obtaining a hierarchy; these aspects contribute to the use of the method to demonstrate various aspects in the literature. For example, there have been studies in which regional competitiveness has been evaluated using the AHP method, applied to the Czech Republic and Slovakia between 2000-2006, taking into account measurable macroeconomic indicators (GDP, gross fixed capital formation, gross domestic expenditures on research and development, net disposable income, knowledge intensive services and patents). The results of these studies showed that GDP has the greatest influence on regional competitiveness. (Kiszová, Nevima, 2012) There can be mentioned similar studies on the same subject, but the methodology implied the usage of the global utility method. Thereby, these studies analyzed regional competitiveness of the firms using the global utility method: "Regional Competitiveness evaluation for Romania" (2008) and "Regional Competitiveness evaluation for Romania" (2011). Combining the two methods might give a touch of originality of this article. In the following subchapters we intend to present these methods and the obtained results.

\section{The global utility method}

The global utility method is a managerial tool used in the decision making process. Using this method, the decision-maker will obtain a hierarchy of the most competitive industries from the North-West region. The utility has values between zero and one and convert different units of characteristics measurement in order to ease their comparison to facilitate the decision. We must follow some steps in order to apply this method correctly.

The first step is to replace the decision-making table with the utility matrix, converting each Cij value in the corresponding utility value $\mathrm{Uij}_{\mathrm{ij}}$.

$$
\mathrm{U}_{\mathrm{ij}}=\frac{\mathrm{C}_{\mathrm{ij}}-\min \mathrm{C}_{\mathrm{ij}}}{\max _{\mathrm{ij}}-\min \mathrm{C}_{\mathrm{ij}}} \text {, for } \mathrm{j}=1, \mathrm{n} \text { (1) }
$$

The second step involves the calculation of the global utility for each decision alternative. Global utility takes into account all characteristics of the decision alternative. It can be determined as the arithmetic mean of the utilities of each decision alternative:

$$
\mathrm{UG}_{\mathrm{j}}=\frac{1}{\mathrm{~m}} \sum_{\mathrm{j}=1}^{\mathrm{n}} \mathrm{U}_{\mathrm{ij}} \text {, for } \mathrm{i}=1, \mathrm{~m}
$$

The optimal decision is the one that has the highest global utility. When calculating the final global utility, the decision-maker considered the same percentage for each analyzed year from 2008 until 2012 (the importance coefficient for each year at regional level was $20 \%$ ).

As it is said, the essence of regional or local competitiveness, at microeconomic level, is represented by the economic agents. Generally speaking, when analyzing regional competitiveness, you must take into account the main indicators regarding the activity of the private companies located in the region. Thus, the decision-maker has established a set of indicators most-commonly used, as the number of companies from every industry, the turnover of these companies and the number of employees. The indicators which are at the base of the evaluation were selected due to 
the fact that it reflects the performance of each industry. They are measurable indicators, offering a high degree of comparability. The indicators $(\mathrm{Ij})$ were calculated as follows:

$$
\mathrm{I}_{1}=\mathrm{C} / \mathrm{P}(3), \mathrm{I}_{2}=\mathrm{T} / \mathrm{P}(4), \mathrm{I}_{3}=\mathrm{E} / \mathrm{P}(5)
$$

Where: $\mathrm{P}$ - Population

$\mathrm{C}$ - companies (number)

$\mathrm{T}$ - Turnover (mill. RON)

E-Employment (number of employees)

According to the methodology and to the NACE Rev.2 Codes, the analyzed industries (which are branches of the manufacturing industry) are:

- Manufacture of food products (I1);

- Manufacture of beverages (I2);

- Manufacture of textiles (I3);

- Manufacture of wearing apparel (I4);

- Manufacture of leather and related products (I5);

- Manufacture of wood (I6);

- Manufacture of paper and paper products (I7);

- Printing and reproduction of recorded media (I8);

- Manufacture of coke and refined petroleum products (I9);

- Manufacture of chemicals and chemical products (I10);

- Manufacture of basic pharmaceutical products and pharmaceutical preparations (I11);

- Manufacture of rubber and plastic products (I12);

- Manufacture of other non-metallic mineral products (I13);

- Manufacture of basic metals (I14);

- Manufacture of fabricated metal products, except machinery and equipment (I15);

- Manufacture of computer, electronic and optical products (I16);

- Manufacture of electrical equipment (I17);

- Manufacture of machinery and equipment (I18);

- Manufacture of motor vehicles, trailers and semi-trailers (I19);

- Manufacture of other transport equipment (I20);

- Manufacture of furniture (I21).

The absolute values of the indicators for the last year of the analysis, used in both methods, are presented in the table below.

Absolute values of the indicators, 2012

\begin{tabular}{|l|c|c|c|}
\hline 2012 & $\begin{array}{c}\text { Number } \\
\text { of firms }\end{array}$ & $\begin{array}{c}\text { Number of } \\
\text { employees }\end{array}$ & $\begin{array}{c}\text { Turnover - } \\
\text { mill. RON }\end{array}$ \\
\hline I1 & 1182 & 15453 & 2473 \\
\hline I2 & 106 & 1576 & 452 \\
\hline I3 & 200 & 2682 & 313 \\
\hline I4 & 660 & 15286 & 695 \\
\hline I5 & 399 & 11811 & 627 \\
\hline I6 & 920 & 7731 & 1163 \\
\hline I7 & 125 & 2117 & 520 \\
\hline I8 & 261 & 2260 & 305 \\
\hline
\end{tabular}




\begin{tabular}{|l|c|c|c|}
\hline I9 & 6 & 97 & 592 \\
\hline I10 & 105 & 1185 & 333 \\
\hline I11 & 16 & 439 & 94 \\
\hline I12 & 458 & 6899 & 1535 \\
\hline I13 & 486 & 5625 & 1217 \\
\hline I14 & 67 & 882 & 334 \\
\hline I15 & 957 & 11843 & 1920 \\
\hline I16 & 130 & 1423 & 309 \\
\hline I17 & 95 & 2210 & 679 \\
\hline I18 & 191 & 3348 & 518 \\
\hline I19 & 53 & 2116 & 445 \\
\hline I20 & 18 & 262 & 24 \\
\hline I21 & 634 & 9839 & 847 \\
\hline
\end{tabular}

Source: National Institute of Statistics

The decision-maker did not encountered difficulties in applying this method and easily got the expected results. The top 5 hierarchy is presented bellow:

- $\quad \mathrm{I} 1=1.517888$

- $\quad \mathrm{I} 15=1.208833$

- $\quad \mathrm{I} 6=1.176860$

- $\quad \mathrm{I} 4=0.992914$

- $\quad \mathrm{I} 21=0.881026$

According to Eurostat, the industries presented above are considered low-tech industries. The industrial manufacturing is grouped into four levels of "technological sophistication": hightechnology, medium-high-technology, medium-low-technology and low-technology. A low-tech industry is characterized by a low R\&D intensity of economic activities ( $R \& D$ expenditures in relation to value added). These industries will be analyzed in more detail in the next chapter.

\section{The Analytic Hierarchy Process}

In order to validate his findings, the decision-maker applied the Analytic Hierarchy Process on the same industries, using the same data for the similar time-frame. So, the competitiveness of the industries can be evaluated through a multi-criteria analysis method, namely the Analytic Hierarchy Process (AHP). The purpose of it is to rank the industries taking into account a set of criteria in the form of measurable indicators (will remain the same as the ones used in the case of the previous method). This method can be used to determine which are the most competitive industries that should be supported in the future through an appreciative method. The decisionmaker knew from the beginning that the proposed methodology is somehow subjective. "AHP provides a method that can quantify the subjective judgement of the decision maker in a way that can be measured". (Gupta et al, 2014)

Even so, it helped him draw some conclusions regarding the potential of these industries and their trends because the AHP method helps breaking the complex problem down into several easily understandable and less complex pieces (subproblems) by establishing priorities.

The multi-criteria analysis helps with the evaluation of more options in case of a problem or complex decision-making situation. In the case at hand, analysing the industries and choosing between them in terms of performance is a problem and a complex decision. It could be the case of the institution that decides to financially support the companies from a certain industry due to the high growth potential. 


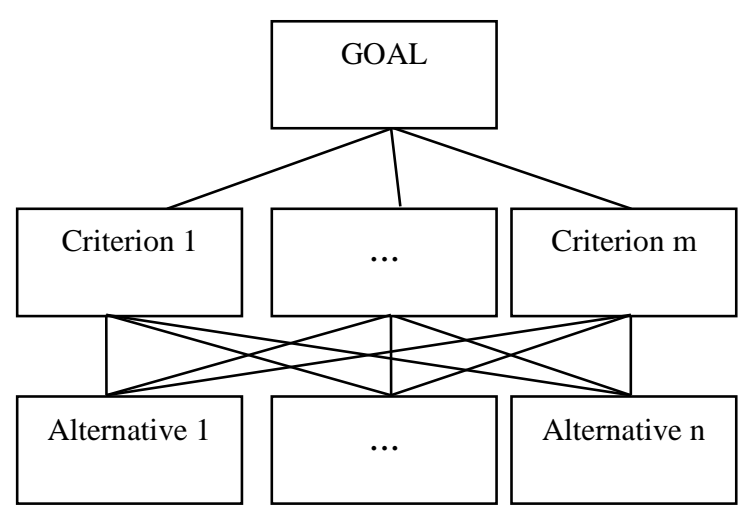

Figure 1. Three-level hierarchic structure

Source: Nevima and Kiszová, 2012

The multi-criteria analysis implies a very well expressed objective; the decision-maker would like to evaluate and to identify the most competitive industries in the North-West region. He assigns a certain weight/value based on its importance for each criterion (the indicators) and then evaluates each alternative (industries) according to each criterion. For each alternative, the sum of all the given grades is computed, the alternatives being ranked based on each result.

Developed by Saaty in the '70s, it allows the decision-makers to represent the interaction of multiple factors, attributes, characteristics, variants or alternatives, based on the construction of a series of"pair comparison" matrices which compare all the criteria between each other. Saaty elaborated a scale for the Intensity of Importance with 9 points which properly reflect the priorities of the comparison between the two elements (Table 2).

Table 2

Saaty's fundamental scale

\begin{tabular}{|c|c|}
\hline Intensity of importance & Definition \\
\hline 1 & Equal importance \\
\hline 3 & Moderate importance \\
\hline 5 & Strong importance \\
\hline 7 & Very strong importance \\
\hline 9 & Extreme importance \\
\hline
\end{tabular}

Source: Saaty 1982

The values $(2,4,6,8)$ are intermediate values or compromise values. They can be used to represent shades of judgment in completing the 5 base evaluations. (Roman, 2012)

"The application of the AHP method involves the following steps: building the hierarchical structure of the decision problem, determining the alternative relative weights compared with the hierarchy attributes and sub-attributes, calculating the total score of each alternative, determining the indicators of consistency by the pairwise comparison and developing the final decision based on the results.” (Stănculescu, 2013)

The pairwise comparison between alternatives has the aim to establish a hierarchy between the decisional alternatives and is used in order to determine the degree of relative importance of the elements. In other words, industries will be compared to each other considering the proposed criteria. It's important to note that if the information is quantitative, as in the present case, the comparison has as the result the ratio between the alternatives values. The comparison should be 
made to determine the relative importance of the criteria to achieve the intended purpose. In the presented case, the decision-maker obtained the following criteria pairwise comparison matrix:

Pairwise comparison matrix

\begin{tabular}{|l|c|c|c|c|c|}
\hline & C1 & C2 & C3 & $\begin{array}{c}\text { Total } \\
\text { score }\end{array}$ & $\begin{array}{c}\text { Overall } \\
\text { weights } \\
\text { or } \\
\text { priorities }\end{array}$ \\
\hline C1 & 1 & 3 & 5 & 9 & 0.586976 \\
\hline C2 & $1 / 3$ & 1 & 7 & 8.33 & 0.332411 \\
\hline C3 & $1 / 5$ & $1 / 7$ & 1 & 1.34 & 0.080614 \\
\hline \multicolumn{6}{|c|}{ Total } \\
\hline
\end{tabular}

Source: Own calculations

Where: $\mathrm{C} 1$ represents the number of companies

$\mathrm{C} 2$ - number of employees

$\mathrm{C} 3$ - turnover

The decision-maker appreciated that the number of companies is three times more important than the number of employees and five times more important than the turnover. The level of concentration may reveal a certain level of competitiveness. From the comparison of the three criteria, a square matrix resulted, that can be considered subjective due to the fact that the criteria ranking is left to the appreciation of the decision-maker. The industries' top 5 can be seen in the table below:

\begin{tabular}{|l|c|c|c|c|c|c|}
\hline & $\mathbf{2 0 0 8}$ & $\mathbf{2 0 0 9}$ & $\mathbf{2 0 1 0}$ & $\mathbf{2 0 1 1}$ & $\mathbf{2 0 1 2}$ & $\mathbf{2 0 0 8 - 2 0 1 2}$ \\
\hline I1 & 0.1474 & 0.1584 & 0.1615 & 0.1629 & 0.1600 & 0.1581 \\
\hline I15 & 0.1183 & 0.1270 & 0.1263 & 0.1288 & 0.1270 & 0.1255 \\
\hline I4 & 0.1164 & 0.1138 & 0.1106 & 0.1116 & 0.1068 & 0.1119 \\
\hline I6 & 0.1284 & 0.1048 & 0.1079 & 0.1090 & 0.1069 & 0.1114 \\
\hline I21 & 0.0975 & 0.0993 & 0.0929 & 0.0883 & 0.0882 & 0.0932 \\
\hline
\end{tabular}

Table 4

Source: Own calculations

Making a comparison, it is clear that the results obtained by applying both methods are similar. The decision-maker can now be sure that the industries that most reflect the industrial profile of the region are food, fabricated metal products, wearing apparel, furniture, and wood. These industries are certified by tradition and even if they have a low technological content, there is potential of growing in the future. The industry of fabricated metal products is a medium-lowtechnology industry, with an increase of the total turnover of $20 \%$ in the analysed time-frame. Even tough the number of the employees in this industry has decreased between 2008-2012, the productivity level has increased with $30 \%$ in the same interval. Also, the market of fabricated metal products reveals clear investment opportunities with low entry barrier. The fact that this industry can easily incorporate technology has convinced the decision-maker to support the economic agents that are active in this field and to establish dedicated specific actions.

We've also observed that in the studied time-frame (2008-2012), the region is competitive in the "Manufacture of food products". This is a low value-added industry with a significant number of firms and employees, but with a quite low level of productivity. Food manufacturing industry is 
leader, not only at regional level, but also nationally, in terms of contribution to gross domestic product (almost 25\%). This industry is putting its stamp on what Cezar Mereuță said in his book ("Foreign majority ownership in the node companies of the main markets in Romania") - "the systemic personality of the Romanian manufacturing industry”. (Mereuță, 2013) This industry is a key strategic part of the regional and national manufacturing industry. One of the solutions for sustaining this industry would be to encourage the firms to invest in technologies in order to increase their level of productivity. In our opinion, a competitive region is one with a significant number of innovative firms and we believe that there is place for innovation in this industry. Another solution to support it could be by promoting the regional food brands abroad and increasing the exports of such products.

The "Manufacture of wearing apparel", a traditional low-technology industry, remains one of the region's specific industries. The wearing apparel industry is relying on the imports of raw materials (fabrics). The comparative advantage could be explained on the basis of the low cost of labour and can easily be lost due to fierce competition. Also, low wages and low labour productivity are characteristics of this industry. Even though the number of companies has decreased by almost $30 \%$ in the time frame, the turnover remained approximately at the same level. This decline can be justified by the inability of firms to adapt to market demands, given that the lohn (under contract) production system has lost ground. It is very important to note that there are regional famous brands in this industry such as Jolidon, Argos, Uniconf and so on and many of these companies have intense commercial activity. These are just some of the arguments at the base of supporting this industry. Wood processing and furniture industries are characterized by a high concentration level in the North-West region. The products made of wood contain a minimal value added and the export of these types of products and the capture of a high value added could be possible through a vertical integration of the industry in the manufacture of furniture and other finished wood objects. Besides this, the region enjoys the presence of a very active furniture cluster (Transylvanian Furniture Cluster) with a mission of developing competitive products for both domestic and foreign markets, and to contribute "to positioning the industry as world range leader for integrated solutions in furniture domain, with high specialization, design and quality", as the cluster representatives are stating. It was demonstrated that clusters contribute to the improvement of regional competitiveness.

\section{Conclusions}

The case study described in this paper is mostly focused on the implementation of the two methods which involves a mathematical algorithm, not difficult to apply by anybody who has a decision making problem. Of course, in the future we intend to develop and to improve this case study trying to make it suitable as teaching material.

In the present paper we tried to find out which are the most competitive industries in the North-West region and we used the AHP multi criteria analysis and the global utility method to do so. We have demonstrated that the North-West region is primarily a traditional low-tech manufacturing region, with the strongest assets lying in the food industry and wearing apparel industry. The results of this paper can be used especially in terms of policy design and could be of help to the local governments or regional institutions and be of interest to future investors.

However, the subjectivism of the two methods may alter the results. There can also be a discussion regarding the chosen indicators of this research. In the future, we would like to take into consideration efficiency indicators like profits or productivity.

The competitiveness of the industries has been captured in an environment in which the transition from industrial economy to new knowledge-based economy occurs. In this context, even the key factors of economy are not the large industrial companies anymore, but the innovative ones, based on knowledge. The technology key factors will no longer be based on automatization and 
mechanization, but on information and communication technology, e-business, computerized production and design. These are some characteristics of the economic environment and should be incorporated in the strategic actions for each industry in part.

As a final conclusion, it is necessary to revitalize the region's industry which is an important platform for growth and employment given the fact that traditional industries have consistently lost the positions on international markets and the newest performing industries have not escaped the low value-added "trap". There is a need to revitalize the traditional industries and to re-launch (reindustrialize), based on new competitive methods, the industries that play an important economic role in terms of employment and investments, because these industries are at a loss of competitiveness. What is important to mention is that most regions maintain a mix between manufacturing and service activities - it is also the case of the North-West region - and could provide competitive product-service combinations. The European Commission, through DG Enterprise and Industry says that it is crucial to understand how services and service innovation can transform manufacturing firms into more competitive ones and to change the industrial configuration. Maybe this is the approach which must be applied in the North-West region.

\section{Acknowledgement}

This work was co-financed from the European Social Fund through Sectoral Operational

Programme Human Resources Development 2007-2013, project number POSDRU/159/1.5/S/134197 "Performance and excellence in doctoral and postdoctoral research in Romanian economics science domain".

\section{References}

1. Bristow, G., 2005. Everyone's a "winner": problematising the discourse of regional competitiveness, Journal of Economic Geography, 5, pp. 285-304.

2. Gupta, R., Jain, B., Madhav, T., Singh, A. R., 2014. Exploration of distribution network for Indian Automobile Industries: AHP approach, International Proceedings of Economics Development and Research, 75, pp. 14-18.

3. Kiszová, Z., Nevima, J., 2012. Evaluation of regional competitiveness in case of the Czech and Slovak Republic using analytic hierarchy process, available online at http://www.wseas.us/e-library/conferences/2012/Zlin/EPRI/EPRI-44.pdf , downloaded at 19.10.2014

4. Mereuţă, C., Pandelică, I., Pandelică, A., 2013. Foreign Majority Ownership in the Node Companies of the Main Markets in Romania, Bucureşti, Editura Economică.

5. Negru-Străuţi, G., Tăucean, I., 2008. Regional Competitiveness evaluation for Romania, Annals of the Oradea University, Fascicle of Management and Technological Engineering, Volume VII (XVII), pp. 2554-2561.

6. Negru-Străuţi, G., Maistor, S., Mocan, M., Pugna, A., 2011. Regional Competitiveness evaluation in Romania, Annals of DAAAM for 2011 \& Proceedings of the 22nd International DAAAM Symposium, Volume 22, No. 1, Published by DAAAM International, Vienna, Austria, EU, pp. 649-650.

7. Roman, M., 2012. Analiza multi-criterială - Manual, available online at http://www.fonduriue.ro/res/filepicker_users/cd25a597fd62/Documente_Suport/Studii/0_Studii_Instrumente_St ructurale/ Pag.3_ACB/19_Analiza_Multicriteriala.pdf, downloaded at 19.10.2014.

8. Saaty, T., 1982. Decision-making for Leaders, California: Wadsworth.

9. Site Eurostat, www.ec.europa.eu, item High technology versus lowtechnology.manufacturing.

10. Stănculescu, O., 2013. Evaluating Romania's regional competitiveness using Analytic Hierarchy Process, RMKT Economists’ Forum, Vol. XVI, No. 115, pp. 171-183. 
11. Thissen, M., Van Oort, F., Diodato, D., Ruijs, A., 2013. Regional competitiveness and smart specialization in Europe. Place-based development in International Economic Networks Interval analysis, Cheltenham, UK, Edward Elgar Publishing Limited. 